\title{
Canadian National Dairy Study: Describing Canadian dairy producer practices and perceptions surrounding cull cow management
}

\author{
S. M. Roche, ${ }^{1,2} \odot$ D. L. Renaud, ${ }^{1,2} \odot$ R. Genore, ${ }^{1} \odot$ D. A. Shock, ${ }^{1} \oplus$ C. Bauman, ${ }^{2} \oplus$ S. Croyle, ${ }^{2} \oplus$ \\ H. W. Barkema, ${ }^{3}$ (D) J. Dubuc, ${ }^{4}$ (D) G. P. Keefe, ${ }^{5}$ (i) and D. F. Kelton ${ }^{2 *}$ (D) \\ ${ }^{1}$ ACER Consulting Ltd., Guelph, Ontario, Canada, N1G 5L3 \\ ${ }^{2}$ Department of Population Medicine, University of Guelph, Guelph, ON, Canada, N1G 2W1 \\ ${ }^{3}$ Department of Production Animal Health, University of Calgary, Calgary, AB, Canada, T2N 1N4 \\ ${ }^{4}$ Faculté de Médecine Vétérinaire, Université de Montréal, St-Hyacinthe, QC, Canada, J2S 2M2 \\ ${ }^{5}$ Department of Health Management, University of Prince Edward Island, Charlottetown, PE, Canada, C1A 4P3
}

\begin{abstract}
Farmer decisions surrounding culling have an important effect on the health and welfare of cull cows. The objectives of this study were to describe the self-reported shipment behaviors of Canadian dairy producers and understand farmer perspectives on the factors that were most influential in their decision to cull a cow. A nationwide survey was administered between March and April 2015 that included 192 questions covering producer background information, farm characteristics, biosecurity practices, disease prevalence, calf health, cow welfare, lameness, milking hygiene, reproduction, and Internet and social media use. The survey yielded a $12 \%$ response rate; a total of 1,076 respondents $(78 \%$ of all survey respondents completed the culling section of the survey) were included in this study for analysis. Approximately 80, 51, and $38 \%$ of respondents reported shipping at least 1 cow to auction, direct to slaughter, and to another dairy farm in the past 12 mo, respectively. Ability of the cow to remain standing (93\% of respondents) and drug withdrawal times (92\% of respondents) were identified as the most important factors for consideration when culling cows. The time between culling decision and when the cow was actually transported was longer for lame cows than sick cows; almost $70 \%$ of respondents reported that cows culled for illness were typically shipped within 1 wk of culling decision, whereas only $51 \%$ of respondents indicated the same was true for lame cows. Last, Canadian dairy producers generally exhibited strong confidence that their culled cows would arrive at slaughter in the same condition as they left, but felt very unsure about
\end{abstract}

Received August 2, 2019.

Accepted December 20, 2019.

*Corresponding author: dkelton@uoguelph.ca knowing the location of their final destination. These results highlight several gaps between producer perceptions and the true situation, and can be used to develop tailored programs and inform policy and regulatory decisions aimed at improving cull cow decisions and cow welfare.

Key words: culling, farmer perception, transportation, compromised cow, behavior

\section{INTRODUCTION}

Commercial dairy herds typically remove approximately $30 \%$ of their herd each year (USDA, 2014; CDIC, 2018). Although many of these are healthy cows culled for poor reproductive performance or low production, many others are culled due to the presence of injury or clinical disease (Hadley et al., 2006; Chiumia et al., 2013; Dahl-Pedersen et al., 2018b). Furthermore, given the effect that these health conditions have on fertility and milk production (Barkema et al., 1994; Bach et al., 2007; De Vliegher et al., 2012), a proportion of cows culled for performance issues may be experiencing some form of underlying disease. As a result, dairy cattle health represents one of the primary reasons for culling. Recent Canadian reports from Canadian milk recording organizations (CanWest DHI, Valacta) suggest that roughly $56 \%$ of all culled cows were removed for a known reason $(n=148,698)$, with some of the most popular reasons being mastitis (19\%), feet and leg problems (12\%), and sickness (8\%; CDIC, 2018). Given the risk that these conditions can pose to cow welfare, the corresponding decisions around when and where to ship each cow become particularly important.

Transportation is a particularly stressful time for cattle regardless of their health status (Dahl-Pedersen et al., 2018c). Given the geographic size of Canada and the United States, transportation is an important risk factor that contributes to compromised health. Cull cows are at higher risk of becoming lame, nonambu- 
latory, wounded, experiencing deterioration of clinical condition, and dying (González et al., 2012; Dahl-Pedersen, et al., 2018c; Stojkov and Fraser, 2018). Studies have shown that the most prominent risk factors for many of these outcomes are lengthy shipping times $(>30 \mathrm{~h})$, long distances $(>400 \mathrm{~km})$, ambient temperatures above $20^{\circ} \mathrm{C}$, and high stocking density (González et al., 2012; Schwartzkopf-Genswein, 2015; Stojkov and Fraser, 2018). Given the potential for conditions to worsen during transport, a producer's assessment of fitness for transport is of paramount importance.

Numerous studies have reported a high prevalence $(\geq 20 \%)$ of health conditions (moderate to severe lameness, mastitis, poor body condition) among cattle observed at auction yards in the United States (Ahola et al., 2011; Nicholson et al., 2013) and Canada (Bovey et al., 2009; González et al., 2012; Moorman et al., 2018). With insufficient enforcement of existing rules and few disincentives to not ship these cows (NFAHW, 2017; Edwards-Callaway et al., 2019), shipment and sale of compromised dairy cattle continues to be an important cow welfare concern for the industry, as discussed by Dahl-Pedersen et al. (2018c).

Although many developed nations have codes of practice and regulations to promote and enforce the shipment of healthy cows, the shipment of compromised cows remains a concern (NFAHW, 2017; EdwardsCallaway et al., 2019). In Canada, the Canadian Food Inspection Agency enforces the Health of Animals Act and Regulations, which regulate the movement of all animals by all modes of transport (CFIA, 2019a). These regulations also specify the conditions that animals may be shipped with, when animals are unfit for transport, and when they may be transported with special provisions. Proposed amendments to these regulations, which will come into effect in 2020, have placed further emphasis on the duration of time dairy cows and calves can be transported without access to feed and water, as well as other requirements pertaining to space, animal handling, cow condition, and time in transit (CFIA, 2019b). Moreover, recent efforts in Canada have begun to focus on building producer awareness of this issue and promoting better assessment of fitness for transport and on-farm decision-making (Stojkov et al., 2018), as research has suggested a low level of agreement between veterinarians, farmers, and livestock drivers when it comes to assessing fitness for transport in dairy cows (Dahl-Pedersen et al., 2018a). Future education, policy, regulation, and other programming efforts require a deeper understanding of how and why producers make the shipment decisions they do. The specific objectives of this study were to describe the self-reported shipment behaviors of Canadian dairy producers and understand farmer perspectives on the factors that were most influential in their decision to cull a cow.

\section{MATERIALS AND METHODS}

\section{Study Design}

This project was part of a larger multi-institutional study, the National Dairy Study, conducted across Canada in collaboration with 4 veterinary schools. Human ethics approval was received from each participating university: University of Calgary (Calgary, AB, Canada; REB no. 14-2481), University of Guelph (Guelph, ON, Canada; REB no. 14DC025), Université de Montréal (Montréal, QC, Canada; 15-007-CERES-D), and University of Prince Edward Island (Charlottetown, PE, Canada; REB no. 6006095).

A national survey was administered to Canadian dairy farmers between March and April, 2015, to collect data on current management practices on Canadian dairy farms. Bauman et al. (2016) and Belage et al. (2017) provide a detailed description of the survey design. Briefly, the survey was developed by dairy research representatives from 4 veterinary schools, and questions were created to address key management and disease priorities based on a previously conducted industry needs assessment (Bauman et al., 2016). The survey was sent to a 16-person advisory group, made up of stakeholders in the industry (4 producers, 4 veterinarians, 4 researchers, and 4 government representatives) for review and pretesting. The final bilingual (English and French) survey consisted of 192 questions, which were divided into the following sections: producer background information, farm characteristics, biosecurity practices, disease prevalence, calf health, cow welfare, lameness, milking hygiene, reproduction, and Internet and social media use. The full survey is available online at http://www.nationaldairystudy.ca/s/NDS-Survey -English.pdf.

A recruitment letter outlining the scope and objectives of the study was mailed to every licensed dairy producer in Canada through their provincial milk organization. A $\$ 20$ gift card was offered as an incentive to complete the survey and was available to the first 250 respondents. The survey was available to be completed online (Qualtrics; https://www.qualtrics.com/), as a paper copy, or by telephone. Paper questionnaires and telephone interviews were entered manually into Qualtrics.

\section{Statistical Analyses}

Data from the survey were downloaded from the survey software, imported, and cleaned in a Microsoft 
Excel (Microsoft Corporation 2018, Redmond, WA) spreadsheet. The cleaned data set was then imported into STATA IC15 (StataCorp LP 2013, College Station, TX) for analysis.

Descriptive analyses were performed on all quantitative variables. The primary variables of interest included the self-reported number cattle leaving the farm and their corresponding destinations (auction/sale/stockyard, abattoir, another farm), the importance of different factors (drug withdrawal status, ability of the cow to stand and stay standing, reproductive status of the cow, current SCC of the cow, BCS of the cow, length of trip for the cow, quota incentive period/season, current cull cow price) and their influence on culling decisions (scored on a 5-point Likert scale from "very unimportant" to "very important"), and self-reported confidence (scale from 1 to 10; a score of 10 being "very confident") regarding cattle condition at the end of the journey. All questions using a 5-point Likert scale were collapsed into 3 points: "very important/important," "moderately important," and "of little importance/very unimportant" (Allen and Seaman, 2007; Jeong and Lee, 2016) to simplify analyses; as this study was focused on whether each factor was viewed as important, neutral, or unimportant. The self-reported time from deciding to cull a cow for lameness to the time she left the farm was compared with the self-reported time from deciding to cull a cow for illness to the time she left the farm using a Kruskal-Wallis equality-of-populations rank test, with a $P$-value of $<0.05$ considered to be significant.

\section{RESULTS}

\section{Respondents}

Overall, a total of 1,373 Canadian producers responded to the survey. This represents a response rate of $12 \%$. Approximately $78 \%$ of respondents completed the survey online, followed by $16 \%$ on hard copy and $6 \%$ by telephone. A total of 297 respondents were removed from the analysis because they reported milking $<10$ cows or did not provide information on the number of milking cows in their herd. The resulting 1,076 respondents (78\% of respondents) were included for analysis. As respondents were permitted to skip any questions they wished, frequency counts were lower for certain questions. Table 1 presents the personal and farm demographic characteristics of the study population.

\section{Cull Cow Destinations}

Approximately $94 \%(1,015 / 1,076)$ of respondents reported permanently removing at least 1 cow (lactating or dry) from their herd in the past 12-mo period.
Most respondents $(80.3 \% ; 816 / 1,015)$ reported sending at least 1 cow to an auction/stockyard/market (Table 2 ), with a median of 15 cows shipped (range: 1-100) over that time period.

\section{Factors Influencing Culling Decisions}

The ability of the cow to stand and stay standing and drug withdrawal status were the most important factors when deciding to cull and transport sick or lame cattle, with $93 \%(1,003 / 1,075)$ and $92 \%(993 / 1,067)$ of respondents choosing "important/very important," respectively. The list of factors producers were asked to respond to and their corresponding ratings are presented in Figure 1.

\section{Time from Culling Decision to Transport}

Respondents were more likely to ship sick cows within 1 wk of deciding to cull when compared with the speed at which lame cows were shipped $(P=0.003$; Figure $2)$. Almost $70 \%$ (689/998) of respondents reported that time between the decision to cull a cow due to illness and time that she actually left the farm was $<1 \mathrm{wk}$.

\section{Producer Confidence}

Respondents were generally confident that most cattle they sent to slaughter in the last 12 mo would arrive at the slaughter facility in the same condition as they left. On a scale from 1 to 10 (with 10 being very confident), $80 \%(781 / 978)$ of respondents scored $\geq 8$; $10 \%$ scored $\leq 5$. Respondents were less confident that they knew which slaughter facility their cattle would arrive at, with $55 \%$ scoring $\leq 5 ; 30 \%$ scored $\leq 1$.

\section{DISCUSSION}

Upon comparison, the study population and the 2015 Canadian dairy population are very similar with respect to region, education, herd size, milk recording status, organic status, housing, and milking system, suggesting the study population represents the Canadian population quite well.

In Canada, the most common route for cull cows to go to slaughter is through a livestock auction (NFAHW, 2017). It is therefore not surprising that the majority of respondents $(80 \%)$ reported shipping at least 1 cow in the past 12-mo period to an auction/stockyard/market. The majority of respondents were highly confident that most of the cattle they sent to slaughter in the last 12 mo would arrive at the slaughter facility in the same condition as they left. Although this study did not observe the condition of cows sent to slaughter, numerous 
Table 1. Comparison of survey respondents in the Canadian national dairy study to the overall Canadian dairy industry (compiled from a variety of sources) by personal and farm-level demographic characteristics

\begin{tabular}{|c|c|c|}
\hline Item & $\begin{array}{l}\text { Study population } \\
(\mathrm{n}=1,076), \text { no. }(\%)\end{array}$ & $\begin{array}{l}2015 \text { Canadian Dairy Industry } \\
\left(\mathrm{n}=11,863^{1}\right), \text { no. }(\%)\end{array}$ \\
\hline \multicolumn{3}{|l|}{ Region $^{1}$} \\
\hline Ontario & $395(36.7)$ & $3,891(32.8)$ \\
\hline Quebec & $468(43.5)$ & $5,848(49.3)$ \\
\hline $\begin{array}{l}\text { Atlantic Canada (Nova Scotia, New Brunswick, Prince Edward Island, } \\
\text { Newfoundland, and Labrador) }\end{array}$ & $78(7.2)$ & $652(5.5)$ \\
\hline \multicolumn{3}{|l|}{ Age $(y r)^{2}$} \\
\hline $30-39$ & $274(25.4)$ & $1,862(15.7)$ \\
\hline $40-49$ & $261(24.2)$ & $3,547(29.9)$ \\
\hline $50-59$ & $312(28.9)$ & $3,345(28.2)$ \\
\hline$>60$ & $82(7.6)$ & $2,087(17.6)$ \\
\hline \multicolumn{3}{|l|}{ Education $^{3}$} \\
\hline Elementary school & $107(9.9)$ & $2,183(18.4)$ \\
\hline Secondary school and grade 12 & $269(25.0)$ & $3,405(28.7)$ \\
\hline \multicolumn{3}{|l|}{ Milk recording ${ }^{4}$} \\
\hline Yes & $998(92.7)$ & $8,897(75.0)$ \\
\hline No & $159(13.7)$ & $2,966(25.0)$ \\
\hline \multicolumn{3}{|l|}{ Herd size ${ }^{4}$} \\
\hline Mean & 77.0 & $9,135(77.0)$ \\
\hline $\mathrm{SD}$ & 80.0 & - \\
\hline \multicolumn{3}{|l|}{ Housing ${ }^{5,6}$} \\
\hline Tiestall & $677(58.7)$ & $8,102(68.3)$ \\
\hline Freestall & $446(38.7)$ & $3,761(31.7)$ \\
\hline Pack & $30(2.6)$ & \\
\hline \multicolumn{3}{|l|}{ Milking system $^{5}$} \\
\hline Pipeline & $681(59.2)$ & $8,174(68.9)$ \\
\hline Parlor & $340(29.5)$ & $2,883(24.3)$ \\
\hline
\end{tabular}

${ }^{1}$ Source: Canadian Dairy Information Centre, Government of Canada.

${ }^{2}$ Source: 2011 Canadian Census of Agriculture, Statistics Canada.

${ }^{3}$ Source: 2016 Canadian Census of Agriculture, Statistics Canada. CEGEP = Collège d'enseignement général et professionnel.

${ }^{4}$ Source: Canadian Dairy Commission, Government of Canada.

${ }^{5}$ Source: received from provincial dairy associations.

${ }^{6}$ Data only available on "loose housing."

studies have demonstrated that cull cows often arrive at sale with compromised health and reduced welfare (Bovey at al., 2009; Ahola et al., 2011; González et al., 2012; Nicholson et al., 2013; Moorman et al., 2018; Dahl-Pedersen et al., 2018c). The levels of self-reported confidence observed in this study therefore suggest a discrepancy between perception and reality, and a gap in producer knowledge of how a cow's condition may degrade while in the marketing system. EdwardsCallaway et al. (2019) also comment that a considerable number of farms in the United States continue to ship compromised cows and that the willingness to ship these cows may be due to a lack of awareness or control over the process, the cow's fate, and available alterna-

Table 2. Frequency and proportion of respondents $(\mathrm{n}=1,015)$ reporting permanently removing at least 1 cow (lactating or dry) from their herd in the past $12 \mathrm{mo}$, and the median number and range of cows shipped by farm, to auction/stockyard/market, direct to slaughter, and another dairy farm

\begin{tabular}{lcc}
\hline Destination & $\begin{array}{c}\text { Number of farms, } \\
\text { no. }(\%)\end{array}$ & $\begin{array}{c}\text { Number of cows shipped } \\
\text { by farm median (range) }\end{array}$ \\
\hline Auction/stockyard/market & $816(80.4)$ & $15(1-100)$ \\
Direct to slaughter & $515(50.7)$ & $10(1-133)$ \\
Another dairy farm & $385(37.9)$ & $5(1-50)$ \\
\hline
\end{tabular}




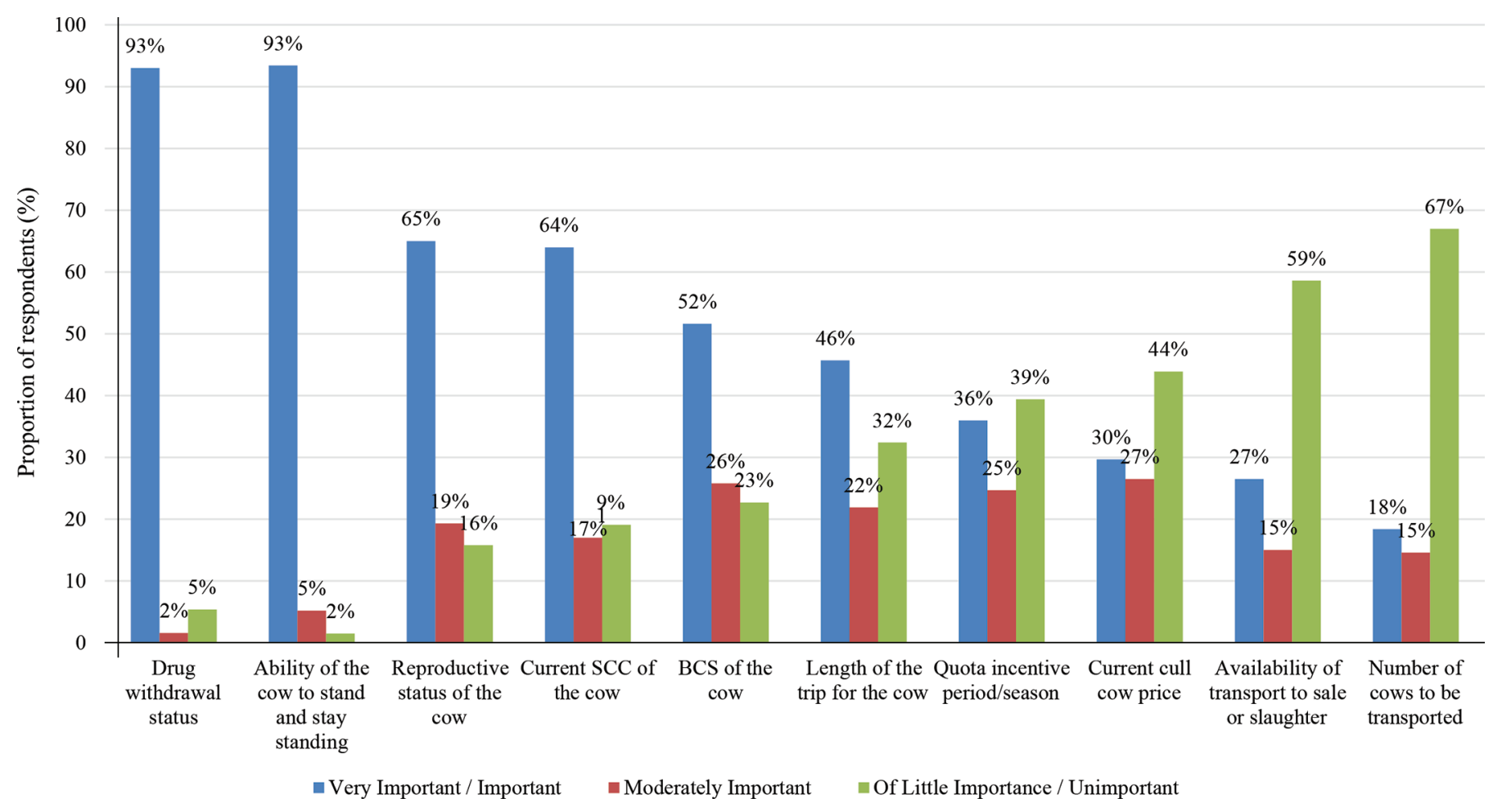

Figure 1. Proportion of respondents' (n = 1,076) views on the importance ("very important/important," "moderately important," "of little importance/unimportant") of several pre-given factors (drug withdrawal status, ability of the cow to stand and stay standing, reproductive status of the cow, current SCC of the cow, BCS of the cow, length of trip for the cow, quota incentive period/season, and current cull cow price) when making culling decisions.

tives. Properly evaluating a cow's condition may also be a factor; Dahl-Pedersen et al. (2018a) demonstrated a low level of agreement between veterinarians, farmers, and livestock drivers when it comes to assessing fitness for transport in dairy cows. Inconsistent views on what "fit for transport" looks like, and the assumption that a cow's condition will not worsen during transport, therefore represent important barriers to decision-making. A recent consensus statement based on expert consultations in Canada concluded that there is an urgent need for producer education and awareness as the assumption that cattle sent to auction will have little delay before being slaughtered is often flawed (Stojkov et al., 2018).

The vast majority of respondents $(93 \%)$ viewed drug withdrawal status and the ability of the cow to stand and stay standing as important factors when deciding to cull a cow. Although these results demonstrate the majority of producers appreciate the importance of these factors, $7 \%$ of respondents did not view these as important. This represents an important risk for food safety and animal welfare and suggests that producers do not universally view any one characteristic as critical to consider before shipping an animal. Opinions varied when respondents considered the importance of other factors relating to cow health, economics, and transport capacity/logistics. Producers generally viewed reproductive status and SCC (factors related to animal health) as the next most important factors, as these are likely the main reasons for culling. However, BCS was only viewed as "very important/important" by $52 \%$ of producers. The view among many producers that BCS is not an important factor to consider represents an important gap in assessing fitness for transport, as we expect a cows condition to worsen during transport and a high proportion of animals with poor condition have been observed at auction yards in the United States (Ahola et al., 2011; Nicholson et al., 2013) and Canada (Bovey et al., 2009; González et al., 2012; Moorman et al., 2018). Interestingly, quota/production incentives and cull cow price (factors related to economics) were not generally viewed as very important, likely because these factors are out of their control and many cows simply must be culled. However, the importance of factors relating to transport capacity/logistics (length of the trip and number of cows to be transported) was mixed. Although $46 \%$ of respondents viewed length of trip for the cow as "very important/important," a lower perceived importance of transport capacity/logistics for many others may be due to assumptions that cattle may 


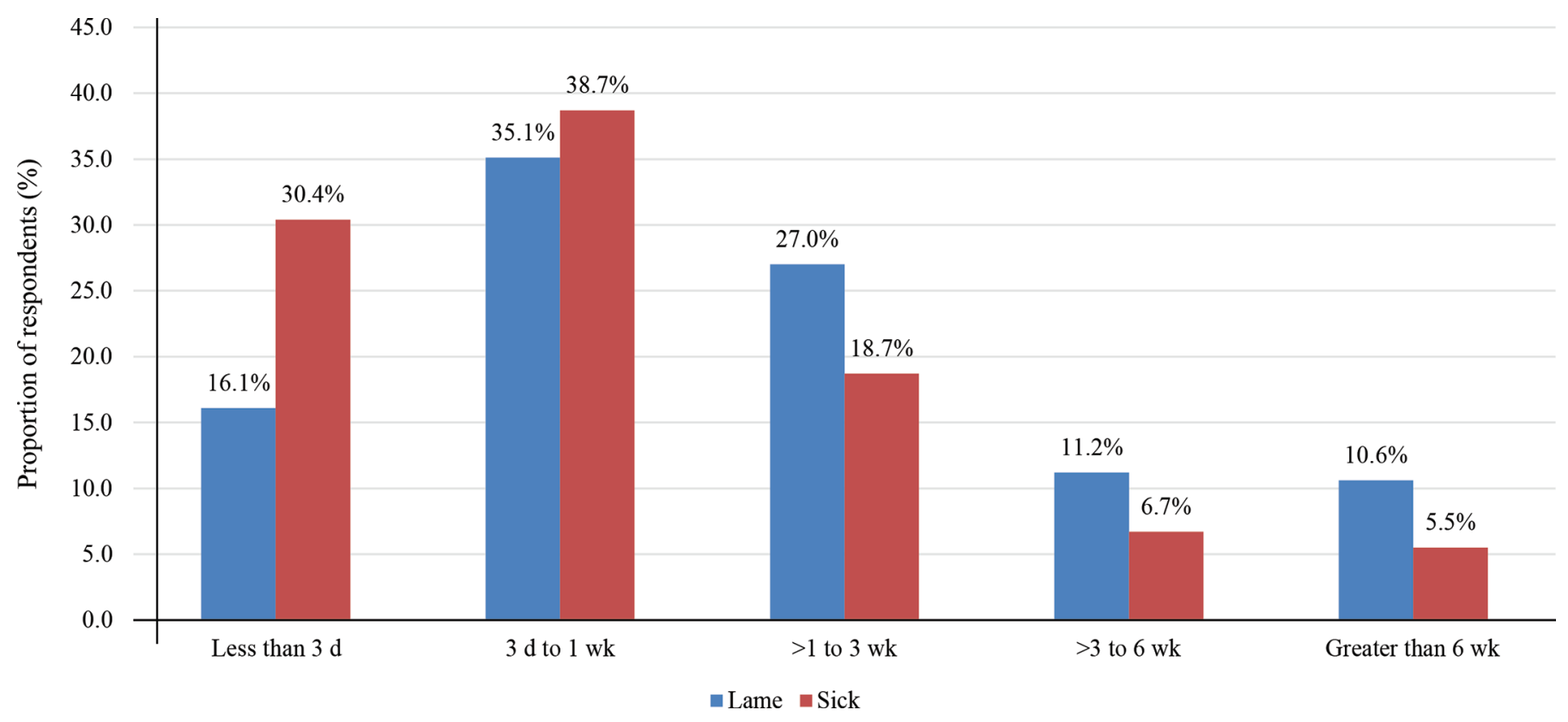

Figure 2. Proportion of respondents $(\mathrm{n}=1,076)$ reporting the length of time between deciding to cull a cow and the time she leaves the farm; responses separately presented for cows culled for lameness and illness.

not travel long distances, an assumption that is often flawed (Stojkov et al., 2018). Similar to the suggestion by Edwards-Callaway et al. (2019), this response may also be reflective of respondent's feeling that this factor is out of their control. In fact, respondents reported a strong lack of confidence in their knowledge of where their cull cows would end up. This lack of perceived importance represents an important gap, as the length of the trip is a particularly important risk factor for cull cow welfare (González et al., 2012; SchwartzkopfGenswein, 2015; Stojkov and Fraser, 2018).

Length of time between the decision to cull and actual shipment of a cow differed by condition, with sick cows reportedly being shipped quicker than lame cows. Over one-quarter of respondents (27\%) noted that lame cows that were slated to be culled were more likely to be shipped between 1 and 3 wk after the decision was made. Without knowledge of the severity of these conditions, it is difficult to make a judgment about whether these decisions are appropriate. However, a decision to cull a cow for a health condition is an important risk factor for poor welfare. Without proper treatment, it is also reasonable to expect these conditions to worsen over time. Therefore, the time lag between decision to cull and physical transport of these cows represents an important cow welfare concern. The risk to cow welfare is heightened further if these cows are sent to auction, as they are likely to spend several more days in transit, where their condition is likely to worsen before they reach their final destination (González et al., 2012;
Schwartzkopf-Genswein, 2015; Stojkov and Fraser, 2018), as opposed to a more expedient method. Assessment of fitness for transport is a critical first step to better management of cull cows. These decisions must then be followed up with action promptly. Future programs must encourage and offer direct to slaughter and emergency on-farm slaughter options, as these are clearly needed. Future efforts to address this problem must also combine educational programming, designed to raise awareness and address knowledge gaps, with new policies and regulations surrounding transportation of compromised animals, and additional infrastructure and transportation options to facilitate Canadian producers to make the right decision for the animal.

As with any survey, the responses received may not necessarily reflect the true practices on the farm due to socially desirable responding, a lack of understanding, different level of knowledge, the inability to accurately answer the question, or a combination of these. For example, the use of self-reported culling estimates in this study may be subject to recall bias. The use of terms such as "direct to slaughter" may also hold different meanings to producers in different provinces, and may have therefore influenced their responses. A low response rate to this survey may also have resulted in selection bias, though the study population and the target population were very similar across all demographic characteristics. These data were collected in 2014 and may not fully reflect the practices or beliefs held by producers today in 2019. However, few new programs, 
policies, or regulations have been imposed regarding cull cows until very recently. The proposed regulatory changes to transportation are likely to begin influencing producer practices and beliefs; however, we believe it is reasonable to expect that before these proposed changes, the data presented within are representative of more recent years in the Canadian dairy industry.

\section{CONCLUSIONS}

The overarching goal of this study was to describe Canadian producer practices and perceptions surrounding cull cow management. The ability of the cow to remain standing and drug withdrawal times were identified as the most important factors for consideration when culling cows. The time between culling decision and when the cow is actually transported was longer for lame cows than sick cows. Last, Canadian dairy producers generally exhibited strong confidence that their culled cows would arrive at slaughter in the same condition as they left, but felt very unsure about knowing the location of their final destination. The levels of selfreported confidence observed may therefore represent an important gap in producer knowledge of how a cow's condition may degrade while in the marketing system. These results highlight several gaps between producer perceptions and the true situation, and can be used to develop tailored programs and inform policy and regulatory decisions aimed at improving cull cow decisions and cow welfare.

\section{ACKNOWLEDGMENTS}

The authors thank all respondents to the $2015 \mathrm{Na}-$ tional Dairy Study, which was funded by Dairy Farmers of Canada (Ottawa, ON, Canada) and Agriculture and Agri-Food Canada (Ottawa, ON, Canada) through the Dairy Research Cluster 2 Program. The authors have not stated any conflicts of interest.

\section{REFERENCES}

Ahola, J. K., H. A. Foster, D. L. VanOverbeke, K. S. Jensen, R. L. Wilson, J. B. Glaze Jr., T. E. Fife, C. W. Gray, S. A. Nash, R. R. Panting, and N. R. Rimbey. 2011. Quality defects in market beef and dairy cows and bulls sold through livestock auction markets in the Western United States: II. Relative effects on selling price. J. Anim. Sci. 89:1484-1495. https://doi.org/10.2527/jas.2010-3171.

Allen, I. E., and C. A. Seaman. 2007. Likert scales and data analyses. Quality Progress: Statistics Roundtable. Accessed Feb. 11, 2020. http://rube.asq.org/quality-progress/2007/07/statistics/likert -scales-and-data-analyses.html.

Bach, A., M. Dinarés, M. Devant, and X. Carré. 2007. Associations between lameness and production, feeding and milking attendance of Holstein cows milked with an automated milking system. J. Dairy Res. 74:40-46. https://doi.org/10.1017/S0022029906002184.
Barkema, H. W., J. D. Western, K. A. S. van Keulen, Y. H. Schukken, and A. Brand. 1994. The effects of lameness on reproductive performance, milk production and culling in Dutch dairy farms. Prev. Vet. Med. 20:249-259.

Bauman, C. A., H. W. Barkema, J. Dubuc, G. P. Keefe, and D. F. Kelton. 2016. Identifying management and disease priorities of Canadian dairy industry stakeholders. J. Dairy Sci. 99:10194-10203. https://doi.org/10.3168/jds.2016-11057.

Belage, E., S. Dufour, C. A. Bauman, A. Q. Jones-Bitton, and D. F. Kelton. 2017. The Canadian National Dairy Study 2015-Adoption of milking practices in Canadian dairy herds. J. Dairy Sci 100:3839-3849.

Bovey, K., P. Lawlis, M. Draper, and T. Widowski. 2009. The health and welfare of cull cows in Ontario. Proc. 9th ISAE North-Am. Regional Mtg. July 17-18, 2009. https://www.appliedethology .org/res/2009_isae_north_american_meeting_proceedings2.pdf.

Canadian Dairy Information Centre (CDIC). 2018. Breed improvement and genetic evaluation: Culling and replacement rates in dairy herds in Canada. https://www.dairyinfo.gc.ca/index_e.php ?s1 $=$ dff-fcil\&s $2=$ mrr-pcle\&s $3=$ cr-tr.

Canadian Food Inspection Agency (CFIA). 2019a. Livestock transport in Canada (brochure). Accessed Feb. 11, 2020. https://www inspection.gc.ca/animals/terrestrial-animals/humane-transport/ livestock-transport-in-canada-brochure-/eng/1363748532198/ 1363748620219.

Canadian Food Inspection Agency (CFIA). 2019b. Health of Animals Regulations Part XII: Transportation of Animals-Regulatory Amendment-Interpretive Guidance for Regulated Parties. Accessed Feb. 11, 2020. http://www.inspection.gc.ca/animals/ terrestrial-animals/humane-transport/interpretive-guidance/eng/ 1480700699158/1480700769747? chap=0.

Chiumia, D., M. G. G. Chagunda, A. I. Macrae, and D. J. Roberts. 2013. Predisposing factors for involuntary culling in Holstein-Friesian dairy cows. J. Dairy Res. 80:45-50. https://doi.org/10.1017/ S002202991200060X.

Dahl-Pedersen, K., L. Foldager, M. S. Herskin, H. Houe, and P. T. Thomsen. 2018a. Lameness scoring and assessment of fitness for transport in dairy cows: Agreement among and between farmers, veterinarians, and livestock drivers. Res. Vet. Sci. 119:162-166. https://doi.org/10.1016/j.rvsc.2018.06.017.

Dahl-Pedersen, K., M. S. Herskin, H. Houe, and P. T. Thomsen. 2018b. A descriptive study of the clinical condition of cull dairy cows before transport to slaughter. Livest. Sci. 218:108-113. https: //doi.org/10.1016/j.livsci.2018.11.001.

Dahl-Pedersen, K., M. S. Herskin, H. Houe, and P. T. Thomsen. 2018c. Risk factors for deterioration of the clinical condition of cull dairy cows during transport to slaughter. Front. Vet. Sci. 5:297-304. https://doi.org/10.3389/fvets.2018.00297.

De Vliegher, S., L. K. Fox, S. Piepers, S. McDougall, and H. W. Barkema. 2012. Invited review: Mastitis in dairy heifers: Nature of the disease, potential impact, prevention, and control. J. Dairy Sci. 95:1025-1040. https://doi.org/10.3168/jds.2010-4074.

Edwards-Callaway, L. N., J. Walker, and C. B. Tucker. 2019. Culling decisions and dairy cattle welfare during transport to slaughter in the United States. Front. Vet. Sci. 5:343. https://doi.org/10.3389/ fvets.2018.00343.

González, L. A., K. S. Schwartzkopf-Genswein, M. Bryan, R. Silasi, and F. Brown. 2012. Relationships between transport conditions and welfare outcomes during commercial long-haul transport of cattle in North America. J. Anim. Sci. 90:3640-3651. https://doi .org/10.2527/jas.2011-4796.

Hadley, G. L., C. A. Wolf, and S. B. Harsh. 2006. Dairy cattle culling patterns, explanations and implications. J. Dairy Sci. 89:22862296. https://doi.org/10.3168/jds.S0022-0302(06)72300-1.

Jeong, H. J., and W. C. Lee. 2016. The level of collapse we are allowed: Comparison of different response scales in safety attitudes questionnaire. Biom. Biostat. Int. J. 4:128-134. https://doi.org/10 $.15406 /$ bbij.2016.04.00100.

Moorman, A. K. G., T. F. Duffield, M. A. Godkin, D. F. Kelton, J. Rau, and D. B. Haley. 2018. Associations between the general 
condition of culled dairy cows and selling price at Ontario auction markets. J. Dairy Sci. 101:10580-10588.

National Farmed Animal Health and Welfare Council (NFAHW) 2017. The management of cull dairy cows in Canada. Accessed Aug. 2, 2019. http://www.ahwcouncil.ca/pdfs/cull-cow/NFAHW \%20Council_Recommendation_The\%20Management\%20of\%20 Cull\%20Dairy\%20Cows\%20in\%20Canada_2017.pdf.

Nicholson, J. D. W., K. L. Nicholson, L. L. Frenzel, R. J. Maddock, R. J. Delmore Jr., T. E. Lawrence, W. R. Henning, T. D. Pringle, D. D. Johnson, J. C. Paschal, R. J. Gill, J. J. Cleere, B. B. Carpenter, R. V. Machen, J. P. Banta, D. S. Hale, D. B. Griffin, and J. W. Savell. 2013. Survey of transportation procedures, management practices, and health assessment related to quality, quantity, and value for market beef and dairy cows and bulls. J. Anim. Sci. 91:5026-5036. https://doi.org/10.2527/jas.2013-6283.

Schwartzkopf-Genswein, K. 2015. Are you doing your best at transporting cull dairy cows to market? Conference proceedings. Western Canadian Dairy Seminar: Advances in Dairy Technology. 27:259-271. Accessed Aug. 2, 2019. https://pdfs.semanticscholar .org/4391/0d690d7bf440a7f88137e005ffd16ad2e1d2.pdf.

Stojkov, J., G. Bowers, M. Draper, T. Duffield, P. Duivenvoorden, M. Groleau, D. Haupstein, R. Peters, J. Pritchard, C. Radom, N. Sillett, W. Skippon, H. Trépanier, and D. Fraser. 2018. Hot topic: Management of cull dairy cows - Consensus of an expert consulta- tion in Canada. J. Dairy Sci. 101:11170-11174. https://doi.org/10 .3168/jds.2018-14919.

Stojkov, J., and D. Fraser. 2018. Transportation of cull dairy cows in British Columbia: Duration and effects on cow condition. J. Anim. Sci. 96(Suppl.3):179. https://doi.org/10.1093/jas/sky404.389.

USDA. 2014. Dairy cattle management practices in the United States, 2014. Accessed Aug. 2, 2019. https://www.aphis.usda.gov/animal _health/nahms/dairy/downloads/dairy14/Dairy14_dr_PartI.pdf.

\section{ORCIDS}

S. M. Roche (1) https://orcid.org/0000-0001-6934-6497

D. L. Renaud ๑ https://orcid.org/0000-0002-3439-3987

R. Genore ๑ https://orcid.org/0000-0001-7737-6047

D. A. Shock (ํ) https://orcid.org/0000-0003-0796-6820

C. Bauman @ https://orcid.org/0000-0001-6706-5456

S. Croyle @ https://orcid.org/0000-0002-1074-8114

H. W. Barkema ๑ https://orcid.org/0000-0002-9678-8378

J. Dubuc (으 https://orcid.org/0000-0003-1013-8372

G. P. Keefe (ำ https://orcid.org/0000-0003-2356-7344

D. F. Kelton () https://orcid.org/0000-0001-9606-7602 